\title{
The Effectiveness of the Flipped Classroom Mode on the English Pronunciation Course
}

\author{
Hongwei Zhang, Xiaomei Du, Xinfa Yuan, Liming Zhang \\ Foreign Language Department, Baoding University, Baoding, China \\ Email: huosiqi2005@126.com
}

Received 31 May 2016; accepted 24 June 2016; published 27 June 2016

Copyright (C) 2016 by authors and Scientific Research Publishing Inc.

This work is licensed under the Creative Commons Attribution International License (CC BY). http://creativecommons.org/licenses/by/4.0/

(c) (i) Open Access

\begin{abstract}
A lot of problems in pronunciation teaching remain unsolved after many years of efforts made by both teachers and researchers. This study is to research into the effectiveness of a comparatively new teaching mode-the flipped classroom-in the English pronunciation course. Mixed methods are adopted in this study in order to seek sufficient evidences for the effectiveness of the flipped classroom teaching mode. The students' final exam scores are compared with those of the students taught with the traditional teaching mode. And individual face-to-face interviews are carried out to investigate the students' attitudes towards the teaching modes. Finally, the conclusion is made that the flipped classroom mode is more effective than the traditional mode in pronunciation teaching.
\end{abstract}

\section{Keywords}

Flipped Classroom, English Pronunciation Course, Effectiveness

\section{Introduction}

The English pronunciation course is a basic course for the English majors in the first year of college study. The importance of English pronunciation in international commutation is self-evident. Yet the English majors' pronunciation usually still stays problematic even after they have had a term's pronunciation course learning. The problem is most serious in ordinary universities or colleges. The reasons are of all kinds. But the ineffectiveness of teaching is in the center of the problem.

Normally, in the pronunciation class, the teacher first teaches the students the position of the tongue and the shape of the mouth, then he/she leads the students to read the vowels and consonants. Some of the students then will be asked to read in front of the class. Errors will be pointed out and more practice will be required. In the whole process, the students seldom get the chance to expose their problems to the teachers, so very few chances 
to get corrected. Individual coaching is impossible because class time is limited and the course is allocated only 32 - 34 teaching hours in a semester. And the rest of the job relies only on the students themselves. Students in ordinary universities or colleges normally have bigger problems with pronunciation and intonation but lower motivation of learning and practice. Even if they have the motivation, a lot of them lack phonetic coding ability (Carroll, 1965), which is essential for autonomous pronunciation learning. And extra individual guidance in learning is missing. So they can get very little profit from the pronunciation course and very tiny slice of hope to achieve success in pronunciation learning.

Chances of individual coaching and guidance tailored to the students' specific problems with the pronunciation of each English sound are in urgent need. Then the normal mode of teaching must be deserted or greatly changed and a new mode must allow individual instruction and guidance under the contemporary education system. And the new mode must make individual instruction and guidance affordable to the teachers who are already very busy with their job and life, and must make learning for the students less stressful, yet more efficient.

Flipped classroom (Hamdan et al.) mode is the answer. In this paper, the author will research into the effectiveness of flipped classroom mode in the English pronunciation course through teaching experimentation, questionnaire, and tests.

\section{Literature Review}

\subsection{Flipped Classroom}

Flipped classroom is an instructional strategy and a type of blended learning that reverses the traditional learning environment by delivering instructional content, often online, outside of the classroom. It moves activities, including those that may have traditionally been considered homework, into the classroom (Wikipedia).

Harvard professor Eric Mazur is an important role in the development of flipped teaching. He found that his approach, which moved information transfer out of the classroom and information assimilation into the classroom, allowed him to coach students in their learning instead of lecture (Crouch \& Mazur, 2001). A teacher's interaction with students in a flipped classroom can be more personalized and less didactic, and students are actively involved in knowledge acquisition and construction as they participate in and evaluate their learning (Alvarez, 2011).

Woodland Park High School chemistry teachers Jonathan Bergmann and Aaron Samsfirst implemented flipped teaching at the high school level in 2007. They assert that there is no one 'right' way to flip a classroom as approaches and teaching styles are diverse, as are needs of schools (Bergmann \& Sams, 2012). In 2011 educators in Michigan's Clintondale High School flipped every classroom (Rosenberg, 2013b). MEF University is the first university in the world that has adopted the "Flipped Classroom" educational model university-wide.

\subsection{Mastery Learning}

Mastery learning is the theoretical basis for flipped classroom mode. In traditional schools, each topic in class receives a fixed amount of time for all students. Flipped mastery classrooms apply a mastery learning model that requires each student to master a topic before moving to the next one (Rosenberg, 2013a).

Mastery learning was briefly popular in the 1920s, and was revived by Benjamin Bloom in 1968. Before flipping, mastery learning was impractical in most schools. It was not possible to give different lectures for different groups of students (Rosenberg, 2013a). In a flipped mastery classroom, students view each lecture and work on each exercise or project when they have mastered the precursors (Bergmann \& Sams, 2012).

\subsection{Previous Studies}

Previous studies on the teaching of pronunciation are massive. But they mostly focus on detecting the problems (Wei, 2013; Liu, 2009), and when they offer solutions, the solutions are still considered under the traditional teaching mode, where there are only two hours of Class A week and 16 - 17 weeks a semester, and where teachers lead the students to read the sounds, checking few individual problems the students have. So, the solutions the previous studies offer are effective only to a quite limited degree. New studies must be done to try out new solutions under a new teaching mode which allows individual coaching to tackle with individual problems within the limited class hours. 
The worldwide studies on flipped classroom mode focused mainly on itsapplication (Gardner, 2012), its effectiveness compared with other teaching modes (Strayer, 2012), the combination of it with other teaching methods (Cannod et al., 2008). In china, the researches started late and mainly focused on the introduction of flipped classroom mode at the beginning. Only in recent years, researches on its application and effectiveness started. These researches are mainly done on the middle school level. Similar researches on the college level are not many (Wang \& Zhang, 2013). And researches on the effectiveness of the flipped classroom mode on pronunciation teaching are rare. Ren (2015) and Yang (2016) focus on the class design of the flipped teaching, leaving the effects unmentioned. Xie (2015) mentions the effects of the flipped classroom mode on the pronunciation course, yet it's still general and lacks specific evidences. So, further researches need to be done to prove the effectiveness of the flipped classroom mode on the English pronunciation course with sound evidences and detailed analysis.

\section{Methodology}

\subsection{Research Purposes}

This paper is to study the effectiveness of the flipped classroom mode on the teaching of pronunciation.

The dependent variables are the teaching effects of the pronunciation course, namely, the students' scores and their comments relating to the help of the teaching modes with their learning difficulties. The independent variable is the application of the flipped classroom mode in the pronunciation course.

The research questions are as follows:

1. Are the scores of the class to which the flipped classroom mode is implemented significantly higher than the class to which the traditional teaching mode is implemented?

2. How do the students comment on the help of the teaching modes with their learning difficulties? Does the flipped classroom mode win their favor?

\subsection{Participants}

The research takes two classes (Class A \& Class B) of freshmen from the English department of a university in the northern part of China as the participants. There are 32 students (30 girls and 2 boys) in each class. They all have the same set of courses in the first semester of college education. Pronunciation and intonation course is a basic course for them. Class A is taught with the flipped classroom mode and Class B with the traditional teaching mode. The two classes are taught by two different teachers but the two teachers share their materials and give the students the same tests of which they will grade the results together. Individual face-to-face interviews are done among students with learning difficulties, 6from each class.

\subsection{Materials}

Some micro-lecture videos are used in the flipped classroom pronunciation teaching. They are short videos, each about 10 minutes long, downloaded by the teacher from "BBC Learning English" program and from "Rachel's English", then adapted to the learners' level by the teacher's adding subtitles and necessary helping information.

Tests are designed by the teachers themselves, with items covering all the knowledge and skills in the pronunciation course.

The interview outline is as follows:

1) Did your first English teacher have accents in speaking English? Did his/her accents influence your English pronunciation?

2) Can you follow the teacher's pace in the pronunciation class? Are there any problems left behind after each class?

3) How did you deal with the problems you had with the sounds? Did you drill?

4) Can you detect, then solve the problems by yourself? Why do you think you could do this? What helped you in doing so? Your talents? Drilling? Or the teacher's guidance? If you couldn't do so, what help do you think you need?

5) When you are in trouble with the sounds, whom would you seek help from?

6) What problems did you have before? Are they solved after the pronunciation course learning?

7) Did you get individual coaching in your pronunciation class? How many chances did you have? How do 
you think of the individual coaching if there were any in your class?

8) Are you satisfied with the pronunciation class? Do you have the confidence to improve your pronunciation in the future? What will influence your confidence?

\subsection{Teaching Design}

In the flipped class, teacher A sends the micro-lectures to the students 3 days ahead of the class. The students learn about the shapes of the mouth and the positions of the tongue in producing the sounds before they go to the class. In the class, the teacher first checks the students' knowledge on the shapes and positions, then checks the students' real production of the sounds, one student after another. If any problems found, the teacher stops to analyze the problems and helps the students to correct. In the process, the teacher makes notes about each student's problems, leaving for future recheck and further help. Other students practice on their own with the help of the videoed lectures and the teacher's suggestions. Students with less problems also help those with more. Most students leave the class with their individual problems analyzed and solved.

In the traditional class, teacher B comes to the class well prepared, but the students nearly unprepared. They have, at most, checked the unfamiliar words in the dictionary. In the class, the teacher first lectures on the shapes of the mouth and the positions of the tongue, then leads the students to read the exercises, stopping from time to time to check some of the students' production of some of the sounds. Most students leave the class without their individual problems revealed, analyzed, then corrected.

\subsection{Methods and Procedure}

One week into the course, when students didn't learn too much, a pre-test for all the English freshmen was done by Teacher A and Teacher B together. Each student's major problems with the English sounds are noted down, though marks are not provided. At the end, the two teachers summed up the problems and found: 1). There were no significant differences between the starting levels of the classes. This was because the students were distributed randomly into different classes at their arrival at the college. 2). The students nearly all have severe problems with the English pronunciation. And their problems are varied. 3). Students also share some common problems, as the lack of sense of liaisons, the problem with the losses of plosion, etc. The two teachers decided to take the results as their starting point in teaching, though adopting different teaching methods, as mentioned in the teaching design (3.4.).

The teaching experimentation is done in the whole semester. At the end of the semester, face-to-face final examination is given one by one to each student from both Class A and Class B, where both teachers A and B present themselves and marks each student's performance. The average score from the two teachers will be the student's final score.

After the exam, separate interviews are given to 12 students from the two classes (6 from each) to learn about their opinions on the help of the teaching modes with their learning difficulties. The interviews are carried out by one of the researchers instead of any of the teachers, so that the students can let out their ideas freely.

\subsection{Data Collection and Analysis}

The results of the exam are uploaded to the college score-management platform and get analyzed automatically. The interviews are recorded then transcribed by the researchers. Then, overall analysis is done to all the forms of data.

\section{Results and Discussions}

\subsection{The Exam Results and Discussions}

From Table 1, it can be seen that the mean of Class A, which is taught with the flipped classroom mode, is higher by 3.75 points than that of Class $\mathrm{B}$, which is taught with the traditional mode. The standard deviation for Class A is 4.43, whereas that of Class B is 5.41. The range in Class A is 16, smaller than that of Class B (24). This means that there are less students in Class A who get low scores. To compare the two mean numbers, t-test is carried out. The alpha level is set at $a<0.01$. The result of calculation is: $t_{o b s}=3.034<t_{\text {crit }}=2.744$. So, the two mean numbers are significantly different. And since the mean of Class A is higher than that of Class B, it 
Table 1. Contrast of the final exam results of Class A and Class B.

\begin{tabular}{ccccccc}
\hline Class & Mean & SD & Maximum & Minimum & N & t \\
A & 90.81 & 4.43 & 98 & 82 & 32 & 3.034 \\
B & 87.06 & 5.41 & 98 & 74 & 32 & \\
\hline
\end{tabular}

$\mathrm{P}<.01 ; \mathrm{df}=62 ; \mathrm{SD}=$ standard deviation; $\mathrm{M}=$ mean.

can be estimated that the scores of the class to which the flipped classroom mode is implemented are significantly higher than the class to which the traditional teaching mode is implemented, that is to say, the first research question is answered positively. The test results show that the flipped classroom mode is more effective in teaching pronunciation than the traditional mode.

\subsection{The Interview Results and Discussions}

To see the students' opinions on the help of the teaching modes with their learning difficulties, interviews were carried out among 12 students (6 from each class). They were interviewed one by one and the results were recorded, transcribed, then analyzed.

The students from Class A favored the flipped classroom teaching mode and attributed their success to the individual coaching the teacher offered in the class. And Class B students have wished that they could have had individual coaching.

It is seen from the answers to question one that twelve students had their education at local primary schools in their cities. And their teachers' pronunciation is not exact, or standard. They all reported strong accents in their first English teacher's English speaking, but they reported not much influence on their pronunciation.

From the answers to question three, it can be concluded that two out of six students in Class Breported that they couldn't keep pace with the teacher, the other four students said they could. And all the six students consider that they could completely understand the shapes of the mouth and the positons of the tongue in producing the sounds. While in Class A, all the six students said that they could keep up with the teacher's schedule. Four students reflected that they have solved all the difficulties and they can easily and clearly identify sounds with similar sounds. The other two deemed that there are still some difficulties existing in their pronunciation.

From the answers to question four, the following messages can be drawn: six students in Class B showed that they solved difficult pronunciations through imitation and listening to the pronunciation from the electronic dictionaries. When asked which factor is the most important reason in solving problems, only two students referred to the teacher's help. Others considered their own practice helped a lot. On the contrary, five students from Class A believed that the guidance of the teacher accounting for a large percentage in the process of their problem solving. Only one student think highly of the listening practice she's done.

The following can be concluded from the answers to question five: five students in Class B reflected that they hoped to get the help from teachers and students. It is obvious that they strongly hoped to get the aid from the teacher, but they have had little chances. While three students in Class A said they hoped to get more help from the teacher and one student says she needs more exercises. The other two students said that they have already mastered the sounds and what they lack is to do more exercises by themselves.

As to ways to solve the learning difficulties, the students said that they would apply different methods, but most students reflect that what they need most is the help from the teacher. Class A students reported different problems they have had, and said they all improved and made great progress after the teacher's individual coaching. Class B students just reported some general problems and said that the problems are still with them.

As for the $7^{\text {th }}$ question, the students from Class B reflected that they had an opportunity to get the teacher's individual coaching only when they are called by the teacher in the class and the chances are rare. Two students viewed that a teacher is responsible for correcting the students' pronunciation. And the individual coaching Class B students have mentioned is different from the individual coaching in the flipped classroom where Class A was involved in. Every student from Class A got individual coaching in every class. The teacher listened to their reading of every sound one by one, then gave them specific guidance. They can correct their wrong pronunciations by listening to the teacher's analysis of their problems, as well as by observing the teacher's way of producing the sounds.

Students from Class B all said that the pronunciation class was not particularly satisfying. Three students said that they have harvest a lot in the semester. In Class A, all reflected that they have harvest a lot in the last seme- 
ster, and individual coaching has played a very important role.

To the last question, all six students in Class Banswered that they are confident to make progress in the future. Two of them mentioned that the teacher's guidance gave them more confidence. Three students thought repeated imitation exercises should account for the largest proportion. One student said her own learning motivation should give her much confidence. While in Class A, all six students said they are confident to improve in the future. They all think that the teacher's guidance for pronunciation learning is the most important reason for their confidence in future progress. Two students feel the teacher's guidance accounts for $80 \%$ of their confidence, and four considered the teacher's guidance could account for $50 \%$ and their repeated imitation could account for the other $50 \%$ of their confidence for future improvement.

\section{Conclusions}

From the discussions above, it can be concluded that the flipped classroom mode of pronunciation teaching is more effective than the traditional teaching mode. The individual coaching in the flipped classroom provides great help to the students in their management with the learning difficulties. It also gives them great confidence in their future learning. The most obvious and direct effect of the flipped classroom mode in pronunciation teaching is that it helps to improve the students' testing scores.

Of course, the present research still leaves many questions unanswered. For example, whether the students' autonomous learning abilities in pronunciation learning are improved with the flipped classroom teaching. And the research also has some defects. The two classes do not share the same teacher, which might have influenced the results of the research. Pretests with exact scores and posttests are necessary if future researches are to be done. Questionnaires could have been carried out to investigate more students' attitudes towards the flipped classroom teaching mode.

\section{Acknowledgements}

Sincere appreciation must be given to all the people who have offered their supports to the research, especially the participants of the interview and the interviewer who has sacrificed a lot of time.

This paper is one of the research results of The Research on the Localization Strategies of Flipped Classroom in Hebei Province College English Major's Teaching (2014YYJG268), which is a Hebei Province College English Teaching Reform Project launched in 2014. So, special gratitude is shown to Hebei Education Department.

\section{References}

Alvarez, B. (2011). Flipping the Classroom: Homework in Class, Lessons at Home. Education Digest: Essential Readings Condensed For Quick Review, 77, 18-21.

Bergmann, J., \& Sams, A. (2012). Flip Your Classroom: Reach Every Student in Every Class Every Day. International Society for Technology in Education, Eugene.

Cannod, G. C., Burge, J. E., \& Helmick, M. T. (2008). Using the Inverted Classroom to Teach Software Engineering. 2008 ACM/IEEE 30th International Conference on Software Engineering, 777-786.

Carroll, J. B. (1965). The Prediction of Success in Foreign Language Training. In R. Glaser (Ed.), Training, Research and Education. New York: Wiley.

Crouch, C., \& Mazur, E. (2001). Peer Instruction: Ten Years of Experience and Results. American Journal of Physics, 69, 970-977.

Gardner, J. G. (2012). The Inverted Agricultural Economics Classroom: A New Way to Teach? A New Way to Learn? Presentation at the Agricultural \& Applied Economics Association's 2012 AAEA Annual Meeting, Seattle. Washington, 12-14.

Hamdan, N., McKnight, P., McKnight, K., \& Arfstrom, K. A Review of Flipped Learning: Flipped Learning Network. http://www.flippedlearning.org/cms/lib07/VA01923112/Centricity/Domain/41/LitReview_FlippedLearning.pdf

Liu, L. (2009). On Problems of College English Phonetic Teaching for English Majors and Suggestions. Journal of Xi'an Polytechnic University, 23, 147-150.

Ren, J. (2015). A Study on the Application of the Flipped Classroom Mode to the English Pronunciation Course. Journal of Suzhou Education Institute, 18, 169-171.

Rosenberg, T. (2013a). In “Flipped” Classrooms, a Method for Mastery. New York Times.

Rosenberg, T. (2013b). Turning Education Upside Down. New York Times. Retrieved 2013-10-11. 
Strayer, J. F. (2012). How Learning in an Inverted Classroom Influences Cooperation, Innovation and Task Orientation. Learning Environments Research, 15, 171-193. http://dx.doi.org/10.1007/s10984-012-9108-4

Wang, X. D., \& Zhang, C. J. Z. (2013). The Application Research of Flipped Classroom in University Teaching_—A Case Study on Professional English of Educational Technology. Modern Educational Technology, 23, 11-16

Wei, J. (2013). Major Problems of Pronunciation Teaching for English Majors of Normal Universities and Countermeasures. Journal of Qilu Normal University, 28, 127-130.

Wikipedia. Flipped Classroom: https://en.wikipedia.org/wiki/Flipped_classroom

Xie, L. (2015). Flipping the Classroom on the Basis of the Internet Video Courses-With the English Pronunciation Course as an Example. Journal of Changchun Education Institute, 31, 93-94.

Yang, J. J. (2016). Flipped Classroom Model Based on Micro-Lecture-Taking Phonology Class of English Majors as an Example. Journal of Shandong Yingcai University, 12, 23-25.

\section{Submit or recommend next manuscript to SCIRP and we will provide best service for you:}

Accepting pre-submission inquiries through Email, Facebook, Linkedin, Twitter, etc A wide selection of journals (inclusive of 9 subjects, more than 200 journals)

Providing a 24-hour high-quality service

User-friendly online submission system

Fair and swift peer-review system

Efficient typesetting and proofreading procedure

Display of the result of downloads and visits, as well as the number of cited articles

Maximum dissemination of your research work

Submit your manuscript at: http://papersubmission.scirp.org/ 